\title{
correspondence
}

\section{Biochar is carbon negative}

To the Editor: The editorial "Half-hearted engineering" and the commentary "Ranking geo-engineering schemes" in Nature Geoscience ${ }^{1,2}$ discuss various schemes for addressing the issue of climate change. We would like to draw attention to the production and burial of biochar as an additional scheme that allows the sequestration of carbon in the soil at the same time as providing fertilizer.

Carbon sequestration through biochar involves pyrolysis or gasification of organic material in low-oxygen conditions from plant waste ${ }^{3}$. The resulting char can be mixed with existing soil, acting as a fertilizer ${ }^{4}$ and sequestering carbon with a mean residence time of about 2,000 years ${ }^{5}$. Biochar production and burial removes carbon dioxide directly from the atmosphere through uptake by plants, allowing, in principle, an actual reduction of atmospheric carbon dioxide levels.

By contrast, conventional carbon capture and storage reduces the carbon dioxide concentrations from exhaust fumes, therefore at best preventing atmospheric carbon dioxide levels from rising further. In addition, it will take at least another decade or so before power plants with carbon capture and storage can be implemented on a large scale. Making biochar is a low-tech process that could be started right now, given the political will.

Based on European emissions of about 1.1 gigatonnes of carbon per year, we estimate that biochar could offset around
9\% of Europe's emissions. We suggest that biochar should be added to the climate change toolkit of renewables, energy saving, and carbon capture and storage.

References

1. Nature Geosci. 1, 719 (2008)

2. Boyd, P. M. Nature Geosci. 1, 722-724 (2008)

3. Harris, E. Nature 442, 624-626 (2006).

4. Glaser, B. Phil. Trans. R. Soc. B 362, 187-196 (2007).

5. Kuzyakov, Y., Subbotina, I., Chen, H., Bogomolova, I. \& Xu, X. L. Soil Biol. Biochem. doi:10.1016/j.soilbio.2008.10.016 (2008).

Bruno Glaser, Mike Parr, Christelle Braun and Goodspeed Kopolo

Biochar Europe, University of Bayreuth, Universitätsstr. 30, D-95440 Bayreuth e-mail: bruno.glaser@uni-bayreuth.de http://www.biochar-europe.org 